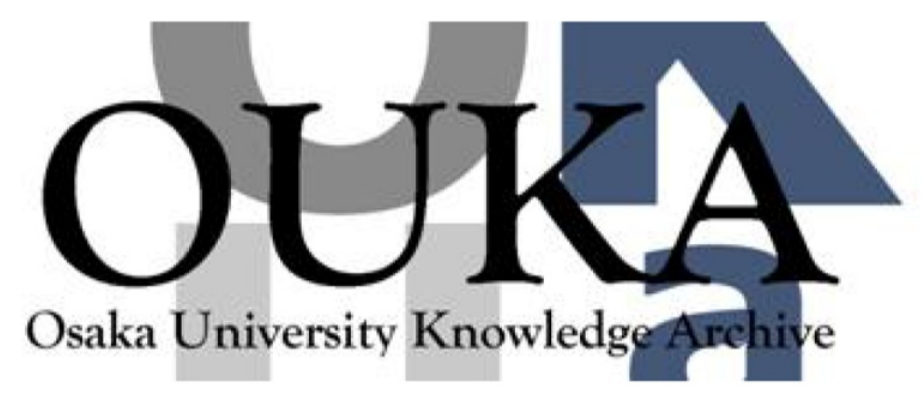

\begin{tabular}{|c|l|}
\hline Title & $\begin{array}{l}\text { Ultrasonic pole figure for the texture of } \\
\text { aluminum alloy }\end{array}$ \\
\hline Author(s) & Hirao, M.; Hara, N. \\
\hline Citation & Applied Physics Letters. 50(20) p. 1411-p. 1412 \\
\hline Issue Date & $1987-05-18$ \\
\hline oaire:version & VoR \\
\hline URL & https://hdl. handle.net/11094/2991 \\
\hline rights & \\
\hline Note & \\
\hline
\end{tabular}

Osaka University Knowledge Archive : OUKA

https://ir. Library. osaka-u. ac. jp/

Osaka University 


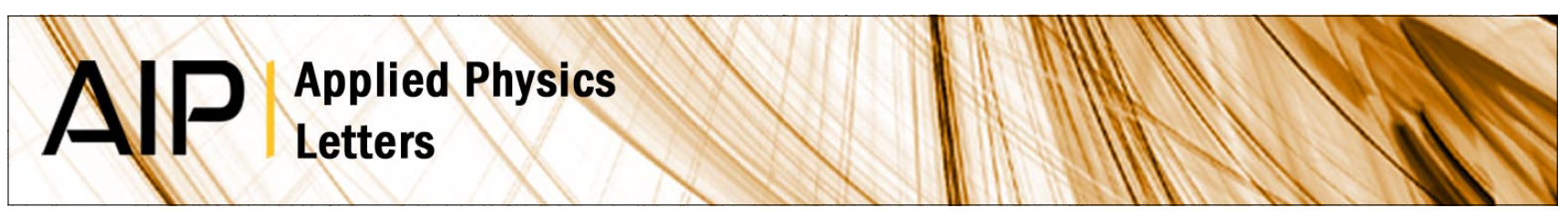

\section{Ultrasonic pole figure for the texture of an aluminum alloy}

M. Hirao and N. Hara

Citation: Appl. Phys. Lett. 50, 1411 (1987); doi: 10.1063/1.97837

View online: http://dx.doi.org/10.1063/1.97837

View Table of Contents: http://apl.aip.org/resource/1/APPLAB/v50/i20

Published by the American Institute of Physics.

\section{Related Articles}

Simultaneous self-collimation of fundamental and second-harmonic in sonic crystals Appl. Phys. Lett. 99, 151905 (2011)

Three-dimensional acoustic wavefront imaging in anisotropic systems by picosecond acoustics J. Appl. Phys. 109, 033507 (2011)

Acoustic reflectivity goniometry of bounded ultrasonic pulses: Experimental verification of numerical models J. Appl. Phys. 104, 064914 (2008)

Rayleigh wave interaction with surface-breaking cracks

J. Appl. Phys. 101, 064906 (2007)

Ultrasonic attenuation in a chain crystal containing resonantly scattering defects

Low Temp. Phys. 32, 270 (2006)

\section{Additional information on Appl. Phys. Lett.}

Journal Homepage: http://apl.aip.org/

Journal Information: http://apl.aip.org/about/about_the_journal

Top downloads: http://apl.aip.org/features/most_downloaded

Information for Authors: http://apl.aip.org/authors

\section{ADVERTISEMENT}

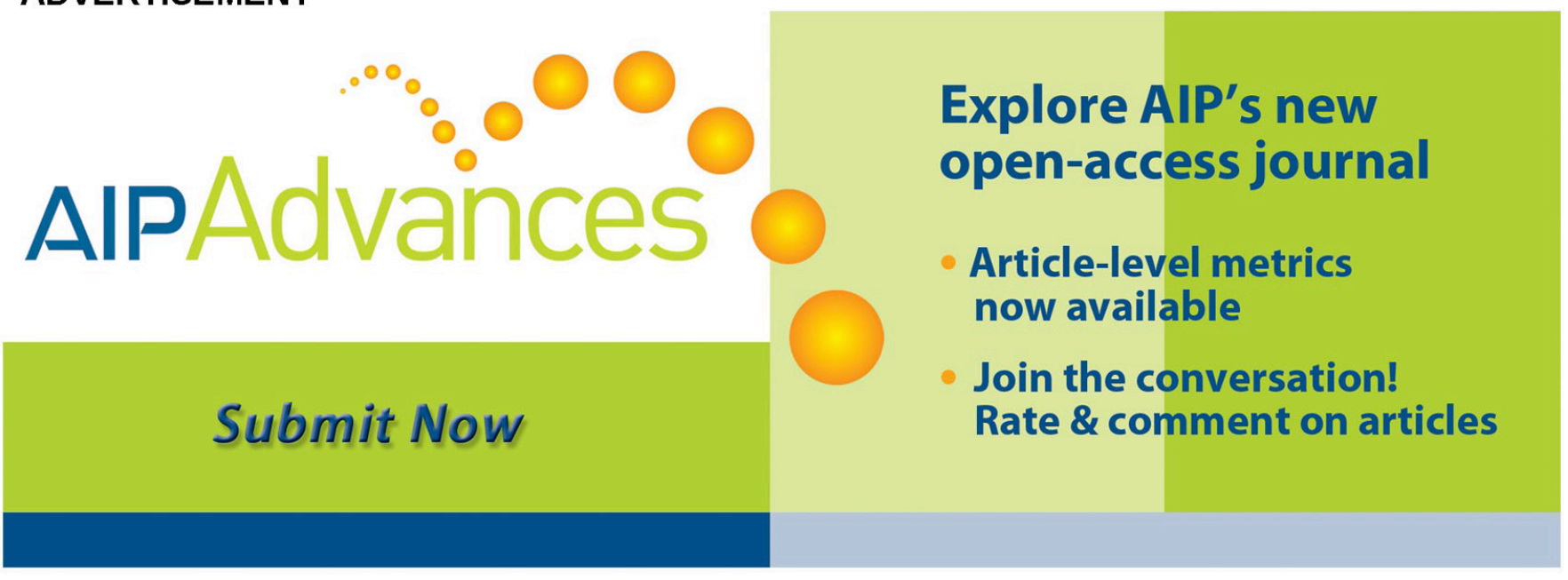




\title{
Ultrasonic pole figure for the texture of aluminum alloy
}

\author{
M. Hirao and N. Hara \\ Faculty of Engineering Science, Osaka University, Toyonaka, Osaka 560, Japan
}

(Received 5 February 1987; accepted for publication 25 March 1987)

\begin{abstract}
An approximate method is proposed to calculate the poie figure diagrams based on the elastic anisotropy measured by ultrasonic velocity experiments. An example is taken from the surface texture of rolled plates of aluminum alloy $7075-\mathrm{T} 651$, for which the angular dependence of the Rayleigh wave is measured in the rolling plane and analyzed to obtain the expansion coefficients of orientation distribution function. The ultrasonic pole figures are favorably compared with the conventional $x-r a y$ pole figures, both demonstrating a single texture centered over (001) [110] orientation.
\end{abstract}

When a polycrystalline meral plastically deforms, the crystailites are rotated with the crystal slip and their certain crystallographic orientation tends to be partially aligned depending on the llow geometry and magnitude. This partiai alignment is called preferred orientation or texture. Most polycrystalline materials as a whole exhibit weak elastic anisotropy due to the texture. The relationship between the texture and the elastic anisotropy has been established by introducing the orientation distribution function (ODF) which gives the probability of crystallite orientation with respect to the sample axes.' The texture slightiy modifies the second-order elastic constants through three independen ODF coefficients, $w_{4 m 0}(m=0,2,4)$, in the case of cubic metals. Therefore, it is now possible to infer the texture from the measurements of anisotropy in the ultrasonic velocities. ${ }^{2,3}$ The ultrasonic method is basically incapable of such detailed texture characterization as the $x$-ray and neutron difraction methods can do, but it makes a nondestructive anc easy inspection possible.

This letter focuses on the surface texture of rolled plates of aluminum alloy 7075-T651. The surface texture can be most conveniently examined using the Rayleigh wave, which penetrates into the depth about a wavelength from the surface. Sayers ${ }^{4}$ and Delsanto et al ${ }^{5,5}$ derived the formula relating the propagation velocity $V_{r}$ and the ODF coefficients in the first-order approximation. When the Rayleigh wave propagates at an angle $\theta$ to the roling direction in the plate surface, $V_{r}$ varies as

$$
\begin{aligned}
V_{r}(\theta)-V_{r o}= & \frac{c}{\rho V_{r o}}\left(r_{0} w_{400}+r_{2} w_{420} \cos 2 \theta\right. \\
& \left.+r_{4} w_{440} \cos 4 \theta\right),
\end{aligned}
$$

where $V_{r o}$ is the velocity in the isotropic case $\left(w_{4 m(2)}=0\right), \rho$ the density, and $c$ the anisotropy factor of the crystal. The coefficients $r_{i}$ depend only on the Poisson ratio: for aluminum, $r_{0}=-1.29, r_{2}=2.45$, and $r_{4}=0.39$. $\mathrm{It}$ is seen then that the $\cos 2 \theta$ term has the largest infuence on the variation of $V_{r}$. This is the case for most solids.

A sing-around experment was conducted for $V_{r}$ 's angular variation. Both ends of an acrylic bar were cut to the critical angle for the Rayleigh wave generation and detection, where two piezoelectric transducers (PZT's) were mounted. The center frequency was $5 \mathrm{MHz}$ and the gauge distance was $131 \mathrm{~mm}$. The bar was rotated around its center at every $5^{\circ}$ by a stepping motor operated with a personal computer, which was aiso used for data acquisition and calculation. Four test plates are sized $200 \times 300 \mathrm{~mm}^{2}$ and of thickness ranging from 25.5 to $12.7 \mathrm{~mm}$ (TP 71 to 74 ).

Typical results of the measurements are shown in Fig. 1 for a quadrant of each plate. All the data were analyzed to obtain the coefficients of constant, $\cos 2 \theta$, and $\cos 4 \theta \mathrm{com}$ ponents. The curve, which is reconstructed using these three components, is drawn in the figure together with the experimental results. The good agreement with the plots indicates that the measured angulat variation of $V_{r}$ can be well interpreted with formula (1). The ODF's coefficients are then determined from the Fourier coefficients as $w_{420}$ $=-0.0010$ and $w_{440}=-0.0051$ for TP 71 . These values were reproducible within 0.00011 for $w_{420}$ and 0.00055 for $w_{440}$.

We need $w_{400}$ and the higher order coefficients of ODF to calculate the pole figures, but they cannot be determined from the ultrasonic experiments. ${ }^{1-3}$ We here propose a procedure for approximating $w_{400}$ and the higher order coeffcients, which is applicable for a single texture. The previous wor $k^{2}$ revealed that the surface texture of 7075-T65! aluminum rolled plates is best described by an ideal orientation, (001) [110]. The delta-function representation of $\mathrm{ODF}^{7}$ for (001) [110] terture gives

$$
\begin{array}{ll}
w_{400}=0.0313, & w_{420}=0, \quad w_{440}=-0.0184, \quad \text { and } \\
w_{600}=0.0081, & w_{620}=0, \quad w_{640}=0.0151, \quad w_{660}=0 .
\end{array}
$$

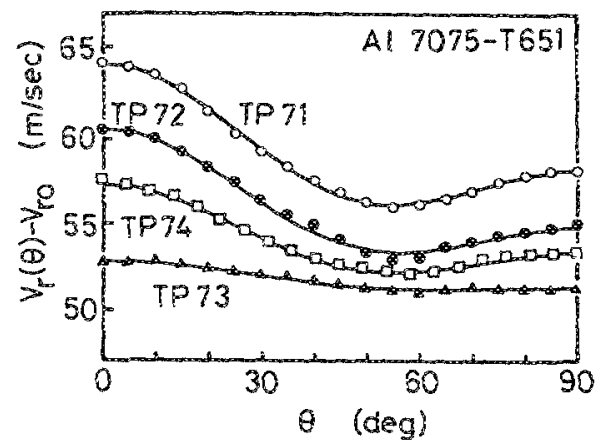

FIO. 1. Raw data and fitted curves for angular dependence of Rayleigh wave velocity for rolled aluminum alloy 7075-T651. Angle $\theta$ is measured from the rolling direction. 


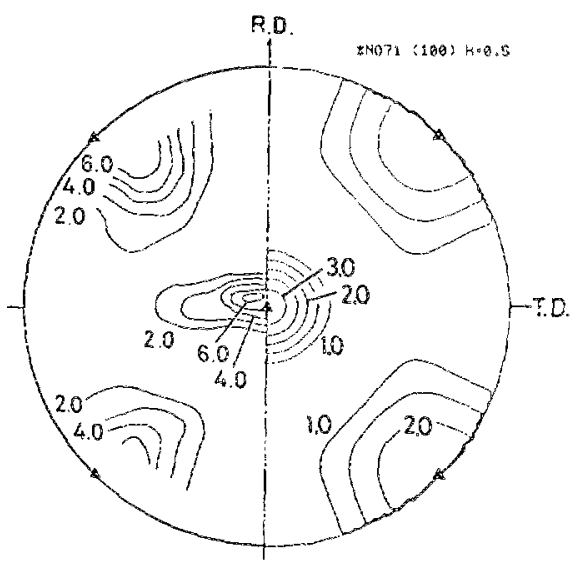

$X$-RAY ULTRASONIC

(100) POLE FIGURE

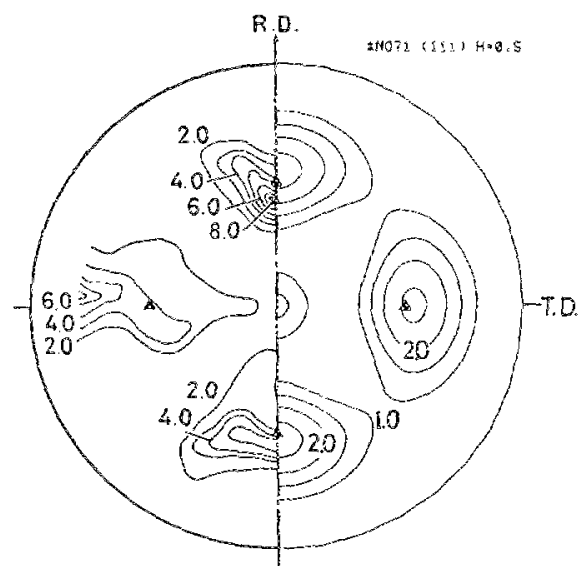

X RAY
Fic. 2. Comparison of ultrasonic pole figures to $x$-ray pole figures $(T P 71)$. (001) [110]. The ultrasonic pole figures $[4 \pi q(\zeta, \eta)$ of $\mathrm{Eq} .(3)]$ involve terms with the fourth- and sixth-order ODF coeficients.
These ODF coefficients apply exactly to the polyerystalline metals with all the crystallites aligned in $(001)[110]$ orientation. We assume that the ratio of measured $w_{440}$ to thus determined $w_{430}$ indicates the "intensity" of that texture. By multiplying the $w$ 's in Eq. (2) with this intensity, we may obtain the approximation for the ODF coefficients that cannot be measured using uitrasonics. They are $w_{400}=0.0094$, $w_{600}=0.0024, w_{640}=0.0045$, and $w_{620}=w_{660}=0$ for $\mathrm{TP}$ 71 , for example. The ultrasonic pole figure is calculated by substituting them in addition to measured $w_{420}$ and $w_{440}$ into

$$
\begin{aligned}
q(\xi, \eta)= & 1 / 4 \pi+S_{4}\left[P_{4}^{0}(\zeta) w_{400}+P_{4}^{2}(\zeta) w_{420} \cos 2 \eta+P_{4}^{4}(\zeta) w_{840} \cos 4 \eta\right] \\
& +S_{6}\left[P_{6}^{0}(\zeta) w_{600}+P_{6}^{2}(\zeta) w_{620} \cos 2 \eta+P_{6}^{4}(\zeta) w_{6,60} \cos 4 \eta+P_{6}^{0}(\zeta) w_{660} \cos 6 \eta\right] .
\end{aligned}
$$

where $P_{i}^{m}(\zeta)$ denotes the normalized associated Legendre function of $\zeta=\cos \chi, \chi$ and $\eta$ being, respectively, the polar and aximathal angies with respect to the samples axes. $w_{420}$ is zero in Eq. (2) but we use the measured $w_{420}$ in Eq. (3). The factors $S_{4}$ and $S_{6}$ take the following values:

$S_{4}=S_{6}=2 \pi$ for (100) pole figure

$S_{4}=-\pi / 2$ and $S_{6}=-13 \pi / 4$ for (110) pole figure

$S_{4}=-4 \pi / 3$ and $S_{6}=32 \pi / 9$ for (111) pole figure.

In Fig. 2 the (100) and (11i) ultrasonic pole figures are compared with those measured by the x-1ay diffractometer (Schulz refiection method). Favorable correspondence suggests that the ultrasonic pole figure would be a useful texture indicator.

The angular variation of the surface skimming SH wave has been separately measured with the same test plates for evaluating $w_{440}{ }^{2}$ The experiments were made using $2 \mathrm{MHz}$ PZT elements. The difference of $w_{440}$ measured by Rayleigh wave and by $\mathrm{SH}$ wave is not negligible, but as small as that observed by Clark et $a l^{8}$ or less. We also found that this difference tends to increase as the plate thickness decreases so far as the four plates used are concerned. This observation suggests that the texture inhomogeneity through thickness would be the major cause of the difference in the values of $w_{440}$.

'C. M. Saycrs, J. Mhys. D 15, 2157 (1982).

'M. Hirao, K. Aoki, and K. Fukuoka, J. Acoust. Soe Am. (in press). 'S. S. Lee, J. F. Smith, and R. B. Thompson, Proceedings of the Symposium on Inter-Relationship of Metallurgical Structure and Formability, to be published from AIME.

C. M. Sayers, Proc. R. Soc, London Ser. A 400,175 (1985)

P. P. Delsanto and A. V. Clark, Jr., J. Acoust. Soc. Am. (in press).

'P. R. Delsanto, R. B. Mignogna, and A. V. Clark, Jr., keview of Progress in Quantitative NDE (to be published).

T. R. Morris, Int. J. Engr. Sci. 8, 49 (1970).

${ }^{*}$ A. V. Clark, Jr., A. Govada, R. B. Thompson, J. F. Smith, G. V. Blessing, P. P. Delsanto, and R. R. Mignogna, Review of Progress of Quantitative NDE (to be published). 